\title{
Konfigurasi Gerbang Tol Pemalang - Batang
}

\author{
Videla Denastyan Agpenta Putra, Wahju Herijanto, dan Catur Arif P. \\ Departemen Teknik Sipil, Institut Teknologi Sepuluh Nopember (ITS) \\ Corresponding Author: catur_ap@ce.its.ac.id
}

\begin{tabular}{l}
\hline ARTIKEL INFO \\
\hline Informasi Artikel \\
Artikel masuk: 1-8-19 \\
Artikel revisi: 26-12-19 \\
Artikel diterima: 26-12-19
\end{tabular}

Kata Kunci

Gerbang Tol,

Tol Pemalang - Batang

\begin{abstract}
ABSTRAK
Jalan tol adalah jalan umum yang merupakan bagian dari sistem jaringan jalan dan sebagai jalan nasional yang penggunanya diwajibkan untuk membayar tol. Pembuatan jalan tol bertujuan untuk mempersingkat waktu tempuh perjalanan dari suatu tempat ke tempat lain. Oleh sebab itu, sebagaimana fungsinya jalan tol harus menyediakan arus yang bebas hambatan agar tujuan jalan tol untuk mempersingkat waktu tempuh perjalanan tercapai. Untuk menikmatinya, para pengguna jalan tol harus membayar sesuai tarif yang berlaku. Perencanaan Konfigurasi Gerbang Tol Pemalang - Batang merencanakan gerbang tol untuk tahun 2019 dan 2034. Metode yang digunakan yaitu Multi Channel Single Phase sebagai struktur dasar proses antrian dan First In First Out sebagai pelayanan antrian. Perencanaan ini diharapkan dapat menghasilkan gerbang tol yang dapat bekerja dengan optimal. Hasil dari Perencanaan Konfigurasi Gerbang Tol Pemalang - Batang pada tahun 2019 untuk gardu tol otomatis khusus terdapat 1 gardu pada setiap arah masuk dan keluar. Untuk gardu tol otomatis gerbang Pemalang terdapat 2 arah masuk dan 3 arah keluar. Gerbang Beji arah masuk dan keluar terdapat 4 gardu. Gerbang Bojong arah masuk dan keluar terdapat 4 gardu. Gerbang Tulis arah masuk dan keluar terdapat 3 gardu. Gerbang Batang arah masuk dan keluar terdapat 2 gardu. Sedangkan untuk gardu tol On Board Unit terdapat 1 pada semua arah masuk dan arah keluar gerbang tol. Pada tahun 2034 terdapat peningkatan jumlah gardu tol sesuai dengan pertumbuhan volume kendaraan.
\end{abstract}

\section{PENDAHULUAN}

Jalan tol adalah jalan bebas hambatan yang dikhususkan untuk kendaraan dengan 2 gandar atau lebih. Pembuatan jalan tol bertujuan untuk mempersingkat waktu tempuh perjalanan dari suatu tempat ke tempat lain. Oleh sebab itu, sebagaimana fungsinya jalan tol harus menyediakan arus yang bebas hambatan agar tujuan jalan tol untuk mempersingkat waktu tempuh perjalanan tercapai.

Jalan tol juga merupakan salah satu alternatif yang digunakan untuk mengatasi kemacetan yang semakin meningkat di Indonesia. Pengguna jalan tol dikenakan kewajiban membayar tol yang digunakan untuk pengembalian investasi, pemeliharaan dan pengembangan jalan tol Proyek pembangunan jalan tol semakin ditingkatkan guna mengimbangi pergerakan masyarakat yang selalu mengalami perpindahan dari satu tempat ke tempat lain. Langkah nyata yang dilakukan pemerintah saat ini adalah dengan menjalankan program pembangunan tol Trans Jawa.

Jalan Tol Trans Jawa adalah jaringan jalan tol yang menghubungkan kota-kota di pulau Jawa. Jalan tol ini merupakan salah satu program pemerintah. Jalan tol ini menghubungkan Provinsi Banten sampai Kota Banyuwangi, Jawa Tengah. Tol trans Jawa sepanjang \pm 1.200 kilometer tersebut melanjutkan jalan-jalan tol yang sekarang sudah ada.
Salah satu bagian dari program tol Trans Jawa adalah proyek pembangunan jalan tol Pemalang - Batang. Untuk mewujudkan pembangunan tol trans jawa, khususnya jalan tol Pemalang - Batang, dibutuhkan perencanaan yang matang serta efektif dan efisien. Tol PemalangBatang dibagi menjadi 2 seksi yaitu Seksi I (PemalangPekalongan) dengan panjang 20,05 km dan seksi II (Pekalongan-Batang) dengan panjang $16,7 \mathrm{~km}$.

Di dalam pelaksanaannya jalan tol yang seharusnya jalan bebas hambatan tetapi sering kali terjadi kemacetan dikarenakan panjangnya antrian di gerbang tol dan kurang seimbangnya antara gerbang tol yang dioperasikan dengan jumlah kendaraan yang masuk ke jalan tol. Melihat fungsi dari jalan tol untuk mempersingkat jarak dan waktu salah satu penunjang fungsi tersebut ialah mengoptimalkan fungsi gerbang tol. Dengan tujuan agar perpindahan barang dan jasa tidak terhambat sehingga meningkatkan perekonomian suatu daerah.

Studi ini memiliki tujuan untuk membuat suatu desain perencanaan jalan tol, khususnya pada perencanaan gerbang tol. Jalan tol yang menjadi objek perencanaan adalah jalan tol Pemalang - Batang.

\section{A. Rumusan Masalah}

Berdasarkan latar belakang masalah yang sudah dipaparakan di atas, permasalahan yang akan di bahas dalam studi ini adalah: 


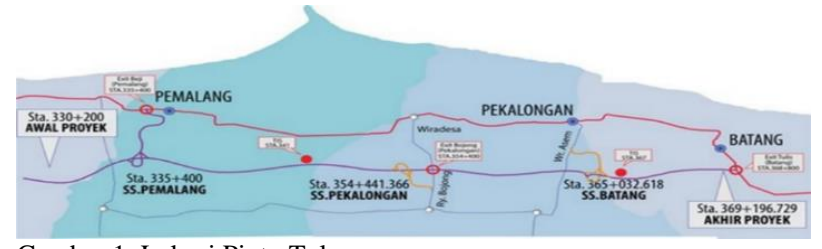

Gambar 1. Lokasi Pintu Tol.

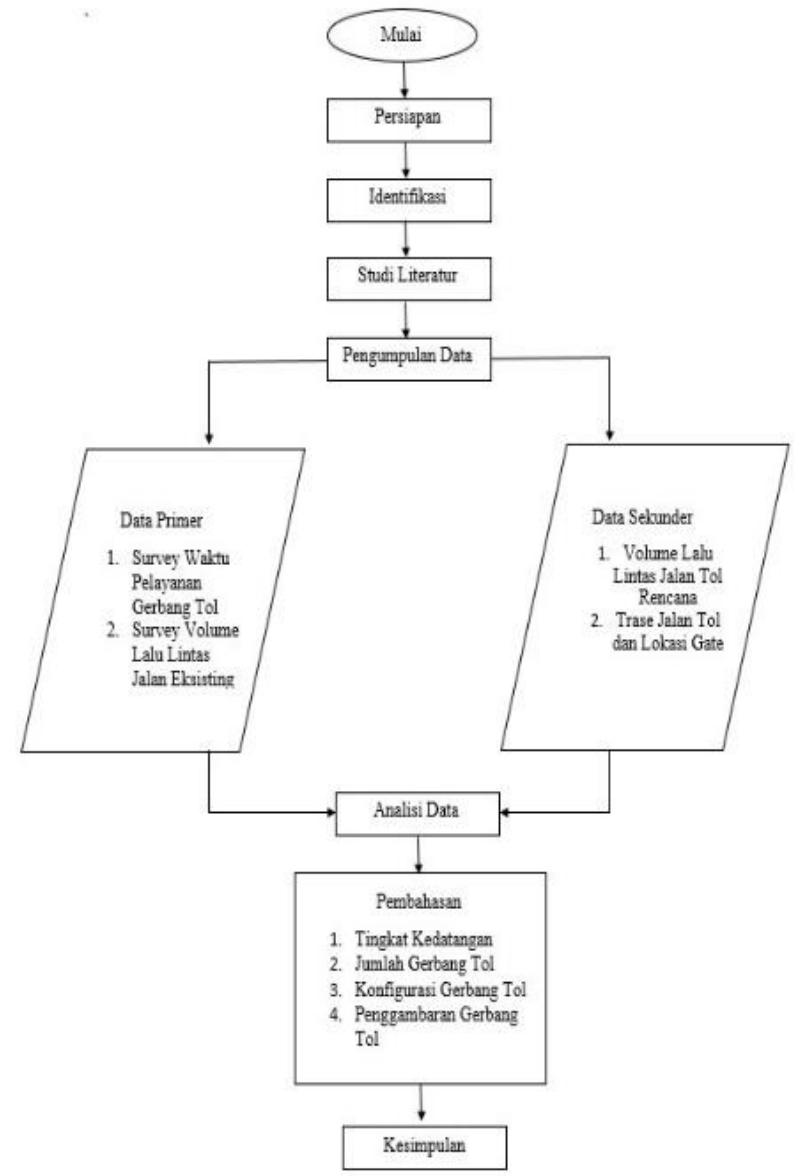

Gambar 2. Diagram Alir Studi.

1. Berapa volume kendaraan yang keluar masuk pintu tol sehingga dapat digunakan untuk merencanakan gerbang tol?

2. Berapa lama waktu pelayanan pada gerbang tol sehingga dapat digunakan untuk merencanakan gerbang tol ?

3. Berapa jumlah gardu tol yang dibutuhkan apabila semua gerbang tol direncanakan dengan sistem Gardu Tol Otomatis (GTO) dan On Board Unit pada tahun 2019 ?

4. Berapa jumlah gardu tol yang dibutuhkan apabila semua gerbang tol direncanakan dengan sistem Gardu Tol Otomatis (GTO) dan On Board Unit pada tahun 2034 ?

5. Bagaimana Lay - out gerbang tol pada tahun 2019 ?

\section{B. Tujuan}

Adapun yang menjadi tujuan dari penyusunan studi ini adalah:

1. Mengetahui lay-out dan jumlah gardu tol yang dibutuhkan serta panjang antrian berdasarkan tingkat kedatangan kendaraan apabila semua gerbang tol direncanakan dengan sistem Gardu Tol Otomatis (GTO) dan On Board Unit.

2. Mengetahui jumlah gardu tol yang dibutuhkan serta panjang antrian berdasarkan tingkat kedatangan kendaraan apabila semua gerbang tol direncanakan dengan Gardu Tol Otomatis (GTO) dan On Board Unit pada tahun 2034.

\section{Batasan Masalah}

Agar dalam studi ini dapat terarah dan mempunyai ruang lingkup yang jelas sehingga tidak menimbulkan kesalahpahaman, serta mempermudah dalam memahami masalah yang akan dibahas, maka perlu adanya suatu batasan masalah. Adapun batasan masalah tersebut adalah:

a. Kendaraan yang di tinjau hanya kendaraan roda 4 atau lebih.

b. Penulis tidak meninjau perkerasan jalan tol

c. Penulis tidak menghitung segi ekonomi dan finansial .

d. Penulis tidak meninjau geometrik jalan tol

e. Penulis tidak membahas perilaku pengendara.

1. Lokasi

Lokasi jalan tol yang telah ditentukan oleh PT.Pemalang-Batang Toll Road terletak di Provinsi Jawa Tengah tepatnya melintasi Kota Pemalang hingga Kota Batang sejauh $+39,2$ kilometer. Proyek ini merupakan bagian dari proyek pembangunan Tol Trans Jawa. Lokasi Gerbang tol ditunjukkan pada Gambar 1.

\section{METODOLOGI}

Metodologi dalam studi ini dapat dilihat pada Gambar 2.

\section{PENGUMPULAN DATA DAN ANALISIS DATA}

\section{A. Data Primer}

Survei waktu pelayanan untuk gardu tol otomatis di gerbang tol Waru 2 Ramp. Sedangkan waktu pelayanan On Board Unit di gerbang tol Cililitan.

\section{B. Data Sekunder}

Data yang di peroleh dari PT.Jasa Marga Pemalang Batang berupa volume lalu lintas, trase jalan, lokasi gerbang tol Pemalang - Batang.

\begin{tabular}{|l|r|r|r|r|}
\hline Tahun & Pemalang - & SS Pemalang - & SS Pekalongan - & \multicolumn{2}{|l|}{ SS B atang - } \\
\hline & SS Pemalang & SS Pekalongan & SS Batang & \multicolumn{1}{|l|}{ Batang } \\
\hline GOL 1 & 8475 & 8386 & 8563 & 8544 \\
\hline GOL 2 & 4157 & 4159 & 4055 & 4050 \\
\hline GOL 3 & 1711 & 1870 & 1854 & 1829 \\
\hline GOL 4 & 890 & 756 & 693 & 707 \\
\hline GOL 5 & 333 & 327 & 320 & 307 \\
\hline TOT AL & $\mathbf{1 5 5 6 6}$ & $\mathbf{1 5 4 9 8}$ & $\mathbf{1 5 4 8 5}$ & $\mathbf{1 5 4 3 7}$ \\
\hline
\end{tabular}

\section{Analisis Data}

Data volume lalu lintas di olah menjadi matrik asal tujuan dengan metode matriks demand and load factor.

Tabel 1. Matrik asal tujuan golongan 1

\begin{tabular}{|l|r|r|r|r|r|}
\hline golongan 1 & Pemal & Beji & Bojong & Tulis & Batang \\
\hline Pemalang & 0 & 996 & 1523 & 806 & 913 \\
\hline Beji & 996 & 0 & 470 & 249 & 282 \\
\hline Bojong & 1523 & 470 & 0 & 938 & 1062 \\
\hline Tulis & 806 & 249 & 938 & 0 & 2000 \\
\hline Batang & 913 & 282 & 1062 & 2000 & 0 \\
\hline
\end{tabular}

Tabel 2. Matrik asal tujuan golongan 2

\begin{tabular}{|l|r|r|l|l|r|}
\hline golongan 2 & Pemal & Beji & Bojong & Tulis & Batang \\
\hline Pemalang & 0 & 1791 & 216 & 20 & 61 \\
\hline Beji & 1791 & 0 & 1283 & 119 & 365 \\
\hline Bojong & 216 & 1283 & 0 & 361 & 1109 \\
\hline Tulis & 20 & 119 & 361 & 0 & 490 \\
\hline Batang & 61 & 365 & 1109 & 490 & 0 \\
\hline
\end{tabular}


Tabel 3. Matrik asal tujuan golongan 3

\begin{tabular}{|l|r|r|l|l|l|}
\hline golongan 3 & Pemal & Beji & Bojong & Tulis & Batang \\
\hline Pemalang & 0 & 808 & 36 & 7 & 6 \\
\hline Beji & 808 & 0 & 655 & 120 & 101 \\
\hline Bojong & 36 & 655 & 0 & 377 & 318 \\
\hline Tulis & 7 & 120 & 377 & 0 & 500 \\
\hline Batang & 6 & 101 & 318 & 500 & 0 \\
\hline
\end{tabular}

Tabel 4. Matrik asal tujuan golongan 4

\begin{tabular}{|l|r|r|l|l|l|}
\hline golongan 4 & Pemal & Beji & Bojong & Tulis & Batang \\
\hline Pemalang & 0 & 360 & 30 & 13 & 11 \\
\hline Beji & 360 & 0 & 186 & 79 & 67 \\
\hline Bojong & 30 & 186 & 0 & 108 & 91 \\
\hline Tulis & 13 & 79 & 108 & 0 & 184 \\
\hline Batang & 11 & 67 & 91 & 184 & 0 \\
\hline
\end{tabular}

Tabel 5. Matrik asal tujuan golongan 5

\begin{tabular}{|l|r|r|l|l|l|}
\hline golongan 5 & Pemal & Beji & Bojong & Tulis & Batang \\
\hline Pemalang & 0 & 149 & 16 & 2 & 1 \\
\hline Beji & 149 & 0 & 122 & 18 & 6 \\
\hline Bojong & 16 & 122 & 0 & 101 & 32 \\
\hline Tulis & 2 & 18 & 101 & 0 & 116 \\
\hline Batang & 1 & 6 & 32 & 116 & 0 \\
\hline
\end{tabular}

\section{PEMBAHASAN}

\section{A. Analisis Tingkat Kedatangan}

Untuk mendapatkan arus jam puncak matrik asal tujuan di kali dengan faktor $k$. Berikut hasil arus jam puncak jalan tol Pemalang - Batang.

Tabel 6. Arus Jam Puncak Golongan I pada Tahun 2019

\begin{tabular}{|l|r|r|r|l|r|}
\hline & Pemalang & Beji & \multicolumn{1}{l|}{ Bojong } & Tulis & Batang \\
\hline Pemalang & 0 & 110 & 168 & 89 & 100 \\
\hline Beji & 110 & 0 & 52 & 27 & 31 \\
\hline Bojong & 168 & 52 & 0 & 103 & 117 \\
\hline Tulis & 89 & 27 & 103 & 0 & 220 \\
\hline Batang & 100 & 31 & 117 & 220 & 0 \\
\hline
\end{tabular}

Tabel 7. Arus Jam Puncak Golongan 2 pada Tahun 2019

\begin{tabular}{|l|r|l|l|l|l|}
\hline & Pemalang & Beji & \multicolumn{1}{l|}{ Bojong } & Tulis & Batang \\
\hline Pemalang & 0 & 197 & 24 & 2 & 7 \\
\hline Beji & 197 & 0 & 141 & 13 & 40 \\
\hline Bojong & 24 & 141 & 0 & 40 & 122 \\
\hline Tulis & 2 & 13 & 40 & 0 & 54 \\
\hline Batang & 7 & 40 & 122 & 54 & 0 \\
\hline
\end{tabular}

Tabel 8. Arus Jam Puncak Golongan 3 pada Tahun 2019

\begin{tabular}{|l|r|l|l|l|l|}
\hline & Pemalang & Beji & Bojong & Tulis & Batang \\
\hline Pemalang & 0 & 89 & 4 & 1 & 1 \\
\hline Beji & 89 & 0 & 72 & 13 & 11 \\
\hline Bojong & 4 & 72 & 0 & 41 & 35 \\
\hline Tulis & 1 & 13 & 41 & 0 & 55 \\
\hline Batang & 1 & 11 & 35 & 55 & 0 \\
\hline
\end{tabular}

Tabel 9. Arus Jam Puncak Golongan 4 pada Tahun 2019

\begin{tabular}{|l|r|l|l|l|r|}
\hline & Pemalang & Beji & Bojong & Tulis & Batang \\
\hline Pemalang & 0 & 40 & 3 & 1 & 1 \\
\hline Beji & 40 & 0 & 20 & 9 & 7 \\
\hline Bojong & 3 & 20 & 0 & 12 & 10 \\
\hline Tulis & 1 & 9 & 12 & 0 & 20 \\
\hline Batang & 1 & 7 & 10 & 20 & 0 \\
\hline
\end{tabular}

Tabel 10. Arus Jam Puncak Golongan 5 pada Tahun 2019

\begin{tabular}{|l|r|l|l|l|l|l|}
\hline & Pemalang & Beji & Bojong & Tulis & Batang \\
\hline Pemalang & 0 & 16 & 2 & 0 & 0 \\
\hline Beji & 16 & 0 & 13 & 2 & 1 \\
\hline Bojong & 2 & 13 & 0 & 11 & 4 \\
\hline Tulis & 0 & 2 & 11 & 0 & 13 \\
\hline Batang & 0 & 1 & 4 & 13 & 0 \\
\hline
\end{tabular}

\section{B. Analisis Jumlah Kendaraan Masuk dan Keluar Gerbang Tol}

Di bawah ini contoh tabel distribusi kendaraan masuk dan keluar golongan 1.

Tabel 11. Distribusi Kendaraan ke Gerbang Tol untuk Golongan 1

\begin{tabular}{|c|c|c|c|c|c|c|}
\hline \multicolumn{7}{|c|}{ Golongan 1} \\
\hline \multicolumn{2}{|c|}{ Zona } & Pemalang & Beji & Bojong & Tulis & Batang \\
\hline Pemalang & Beji & 110 & 110 & & & \\
\hline Pemalang & Bojong & 168 & & 168 & & \\
\hline Pemalang & Tulis & 89 & & & 89 & \\
\hline Pemalang & Batang & 100 & & & & 100 \\
\hline Beji & Bojong & & 52 & 52 & & \\
\hline Beji & Tulis & & 27 & & 27 & \\
\hline Beji & Batang & & 31 & & & 31 \\
\hline Beji & Pemalang & 110 & 110 & & & \\
\hline Bojong & Tulis & & & 103 & 103 & \\
\hline Bojong & Batang & & & 117 & & 117 \\
\hline Bojong & Beji & & 52 & 52 & & \\
\hline Bojong & Pemalang & 168 & & 168 & & \\
\hline Tulis & Batang & & & & 220 & 220 \\
\hline Tulis & Bojong & & & 103 & 103 & \\
\hline Tulis & Beji & & 27 & & 27 & \\
\hline Tulis & Pemalang & 89 & & & 89 & \\
\hline Batang & Tulis & & & & 220 & 220 \\
\hline Batang & Bojong & & & 117 & & 117 \\
\hline Batang & Beji & & 31 & & & 31 \\
\hline Batang & Pemalang & 100 & & & & 100 \\
\hline
\end{tabular}

Tabel 12. Jumlah Kendaraan Masuk Gerbang

\begin{tabular}{|c|r|r|r|r|r|}
\hline \multicolumn{7}{|c|}{ Jumlah Kendaraan Masuk gerbang } \\
\hline Golongan & Pemalang & \multicolumn{1}{c|}{ Beji } & Bojong & Tulis & Batang \\
\hline 1 & 466 & 220 & 439 & 439 & 468 \\
\hline 2 & 122 & 391 & 327 & 109 & 223 \\
\hline 3 & 94 & 185 & 152 & 111 & 102 \\
\hline 4 & 46 & 76 & 46 & 42 & 39 \\
\hline 5 & 18 & 32 & 30 & 26 & 17 \\
\hline Total & 746 & 905 & 994 & 728 & 849 \\
\hline
\end{tabular}

Tabel 13. Jumlah Kendaraan Keluar Gerbang Jumlah Kendaraan Keluar Gerbang

\begin{tabular}{|c|r|r|r|r|r|}
\hline \multicolumn{7}{|c|}{ Jumlah Kendaraan Keluar Gerbang } \\
\hline Golongan & Pemalang & Beji & Bojong & \multicolumn{1}{c|}{ Tulis } & Batang \\
\hline 1 & 466 & 110 & 439 & 439 & 468 \\
\hline 2 & 230 & 283 & 327 & 109 & 223 \\
\hline 3 & 95 & 185 & 152 & 110 & 102 \\
\hline 4 & 46 & 76 & 46 & 42 & 39 \\
\hline 5 & 18 & 32 & 30 & 26 & 17 \\
\hline Total & 855 & 687 & 994 & 727 & 849 \\
\hline
\end{tabular}

\section{Analisa Waktu Pelayanan}

Waktu pelayanan yang digunakan untuk perencanaan gerbang tol Pemalang - Batang dari hasil pelaksanaan survei di gerbang tol.

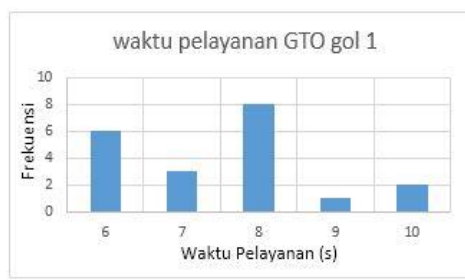

Gambar 3. Waktu Pelayanan Golongan 1.

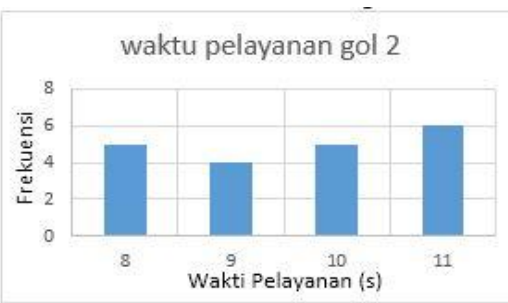

Grafik 4. Waktu Pelayanan Golongan 2. 


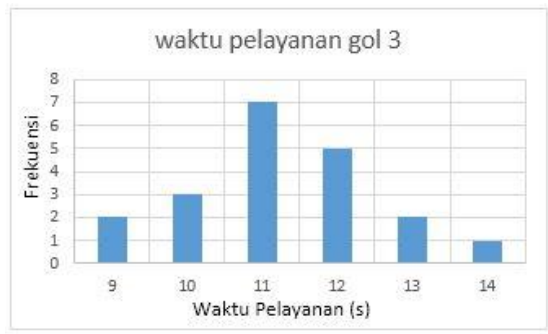

Grafik 5. Waktu Pelayanan Golongan 3.

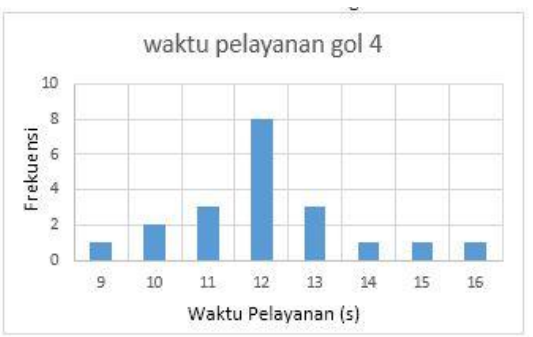

Grafik 6. Waktu Pelayanan Golongan 4.

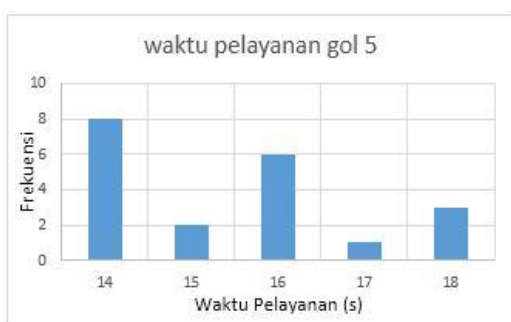

Grafik 7. Waktu Pelayanan Golongan 5.

Dalam menentukan waktu pelayanan dari setiap golongan kendaraan dilihat dari nilai rata-rata (mean), peresentase kumulatif $50 \%$, dan persentase kumulatif $80 \%$. Dan untuk menentukannya dari 3 nilai yang disebutkan sebelumnya diperiksa dengan nilai median dan modus. Setelah itu dicari nilai yang lebih dekat dengan nilai median dan modus. Sehingga setelah dianalisis waktu pelayanan untuk golongan I 8 detik, golongan II 10 detik, golongan III 11 detik, golonga IV 12 detik, golongan V 15 detik dan untuk gardu On Board Unit 5 detik.

Tabel 14. Tingkat Pelayanan Gerbang Tol

\begin{tabular}{|c|c|c|c|}
\hline Gerbang Tol & \multicolumn{2}{|c|}{ Gardu } & $\mu$ (kend/jam) \\
\hline \multirow{6}{*}{ Pemalang } & \multirow{2}{*}{ GTO } & Masuk & 254 \\
\hline & & Keluar & 276 \\
\hline & \multirow{2}{*}{ GTO Khusus } & Masuk & 450 \\
\hline & & Keluar & 450 \\
\hline & \multirow{2}{*}{ OBU } & Masuk & 720 \\
\hline & & Keluar & 720 \\
\hline \multirow{6}{*}{ Beji } & \multirow{2}{*}{ GTO } & Masuk & 227 \\
\hline & & Keluar & 192 \\
\hline & \multirow{2}{*}{ GTO Khusus } & Masuk & 450 \\
\hline & & Keluar & 450 \\
\hline & \multirow{2}{*}{$\mathrm{OBU}$} & Masuk & 720 \\
\hline & & Keluar & 720 \\
\hline \multirow{6}{*}{ Bojong } & \multirow{2}{*}{ GTO } & Masuk & 258 \\
\hline & & Keluar & 258 \\
\hline & \multirow{2}{*}{ GTO Khusus } & Masuk & 450 \\
\hline & & Keluar & 450 \\
\hline & \multirow{2}{*}{ OBU } & Masuk & 720 \\
\hline & & Keluar & 720 \\
\hline \multirow{6}{*}{ Tulis } & \multirow{2}{*}{ GTO } & Masuk & 234 \\
\hline & & Keluar & 234 \\
\hline & \multirow{2}{*}{ GTO Khusus } & Masuk & 450 \\
\hline & & Keluar & 450 \\
\hline & \multirow{2}{*}{ OBU } & Masuk & 720 \\
\hline & & Keluar & 720 \\
\hline \multirow{4}{*}{ Batang } & \multirow{2}{*}{ GTO } & Masuk & 276 \\
\hline & & Keluar & 276 \\
\hline & \multirow{2}{*}{ GTO Khusus } & Masuk & 450 \\
\hline & & Keluar & 450 \\
\hline
\end{tabular}

\section{Analisis Tingkat Pelayanan}

Pada perencanaan gerbang tol Pemalang-Batang memerlukan tingkat pelayanan untuk keselurahan gardu tol yang direncanakan pada tiap gerbang. Analisis tingkat pelayanan ini menggunakan data waktu pelayanan dari tiap golongan yang sudah dianalisis sebelumnya dan tingkat kedatangan dari masing-masing golongan kendaraan pada tiap gerbang. (Tabel 14)

\section{E. Analisis Intensitas Gerbang Tol}

Menggunakan rumus:

$$
\begin{aligned}
& \mathrm{N}=\frac{\lambda}{\mu-\lambda}=\frac{\rho}{1-\rho} \\
& \rho=\frac{\lambda}{\mu}
\end{aligned}
$$

dengan persyaratan bahwa nilai tersebut selalu harus lebih kecil dari 1 (May, 1990:361) [1]

Gardu Tol Masuk

Jumlah (N) gardu tol otomatis khusus Gol I : 1 gardu

Jumlah (N) gardu tol otomatis : : 2 gardu

Jumlah gardu On Board Unit : : 1 gardu

$\lambda 1$ gardu tol otomatis khusus Gol. I : 233 kend./jam

$\lambda 2$ gardu tol otomatis

$\lambda 3$ gardu On Board Unit

: 397 kend./jam

$\mu 2$ gardu tol otomatis

$\mu 3$ gardu On Board Unit

: 254 kend./jam

: 720 kend./jam

1. Gardu tol otomatis khusus:

$\rho 1=\frac{\lambda 1 / N 1}{\mu 1}$

$\rho 1=\frac{233 / 1}{450}$

$\rho 1=0.517<1(O K)$

2. Gardu tol otomatis:

$\rho 2=\frac{\lambda 2 / N 2}{\mu 2}$

$\rho 2=\frac{397 / 2}{254}$

$\rho 2=0.779<1(O K)$

3. Gardu tol On Board Unit:

$\rho 3=\frac{\lambda 3 / N 3}{\mu 3}$

$\rho 3=\frac{117 / 1}{720}$

$\rho 3=0.162<1(O K)$

Dikarenakan $\rho 1, \rho 2$ dan $\rho 3$ yang dianalisis $<1$, maka intensitas lalu lintas pada gerbang tol Pemalang arah masuk aman.

Tabel 15 adalah intensitas gerbang tol Pemalang Batang.

\section{F. Analisis Antrian pada Gerbang Tol Tahun 2019}

Analisis antrian pada gerbang dilakukan untuk mengetahui panjang antrian dan waktu antrian pada gerbang tol yang di rencanakan. Dibawah ini table hasil perhitungan analisis antrian FIFO Menurut A.K. Erlang dan Kakiay [2][3].

\section{KESIMPULAN DAN SARAN}

\section{A. Kesimpulan}

Berdasarkan hasil analisis dan pembahasan pada bab sebelumnya, dapat diambil kesimpulan sebagai berikut: 
Tabel 15. Intensitas Lalu Lintas Gerbang Tol Pemalang -Batang Tahun 2019

\begin{tabular}{|c|c|c|c|c|c|c|}
\hline $\begin{array}{c}\text { Gerbang } \\
\text { Tol }\end{array}$ & \multicolumn{2}{|c|}{ Gardu } & $\mathrm{N}$ & $\lambda$ & $\mu$ & $\rho$ \\
\hline \multirow{6}{*}{ Pemalang } & \multirow{2}{*}{ GTO } & Masuk & 2 & 397 & 254 & 0.779 \\
\hline & & Keluar & 3 & 506 & 276 & 0.609 \\
\hline & \multirow{2}{*}{$\begin{array}{c}\text { GTO } \\
\text { Khusus }\end{array}$} & Masuk & 1 & 233 & 450 & 0.518 \\
\hline & & Keluar & 1 & 233 & 450 & 0.518 \\
\hline & \multirow{2}{*}{ OBU } & Masuk & 1 & 117 & 720 & 0.162 \\
\hline & & Keluar & 1 & 117 & 720 & 0.162 \\
\hline \multirow{6}{*}{ Beji } & \multirow{2}{*}{ GTO } & Masuk & 4 & 740 & 228 & 0.813 \\
\hline & & Keluar & 4 & 604 & 192 & 0.785 \\
\hline & \multirow{2}{*}{$\begin{array}{c}\text { GTO } \\
\text { Khusus }\end{array}$} & Masuk & 1 & 110 & 450 & 0.244 \\
\hline & & Keluar & 1 & 55 & 450 & 0.122 \\
\hline & \multirow{2}{*}{ OBU } & Masuk & 1 & 55 & 720 & 0.076 \\
\hline & & Keluar & 1 & 27 & 720 & 0.038 \\
\hline \multirow{6}{*}{ Bojong } & \multirow{2}{*}{ GTO } & Masuk & 4 & 664 & 258 & 0.644 \\
\hline & & Keluar & 4 & 665 & 258 & 0.644 \\
\hline & \multirow{2}{*}{$\begin{array}{c}\text { GTO } \\
\text { Khusus }\end{array}$} & Masuk & 1 & 220 & 450 & 0.488 \\
\hline & & Keluar & 1 & 220 & 450 & 0.488 \\
\hline & \multirow{2}{*}{$\mathrm{OBU}$} & Masuk & 1 & 110 & 720 & 0.153 \\
\hline & & Keluar & 1 & 110 & 720 & 0.152 \\
\hline \multirow{6}{*}{ Tulis } & \multirow{2}{*}{ GTO } & Masuk & 3 & 398 & 233 & 0.568 \\
\hline & & Keluar & 3 & 398 & 234 & 0.566 \\
\hline & \multirow{2}{*}{$\begin{array}{c}\text { GTO } \\
\text { Khusus }\end{array}$} & Masuk & 1 & 220 & 450 & 0.488 \\
\hline & & Keluar & 1 & 220 & 450 & 0.488 \\
\hline & \multirow{2}{*}{$\mathrm{OBU}$} & Masuk & 1 & 110 & 720 & 0.153 \\
\hline & & Keluar & 1 & 110 & 720 & 0.152 \\
\hline \multirow{6}{*}{ Batang } & \multirow{2}{*}{ GTO } & Masuk & 2 & 279 & 276 & 0.505 \\
\hline & & Keluar & 2 & 281 & 276 & 0.509 \\
\hline & \multirow{2}{*}{$\begin{array}{c}\text { GTO } \\
\text { Khusus }\end{array}$} & Masuk & 1 & 234 & 450 & 0.520 \\
\hline & & Keluar & 1 & 234 & 450 & 0.520 \\
\hline & \multirow{2}{*}{ OBU } & Masuk & 1 & 117 & 720 & 0.163 \\
\hline & & Keluar & 1 & 117 & 720 & 0.163 \\
\hline
\end{tabular}

1. Volume kendaraan pada gerbang tol Pemalang

Batang pada tahun 2019 sebagai berikut:

a. Gerbang I Pemalang, tingkat kedatangan kendaraan arah masuk sebesar $746 \mathrm{emp} / \mathrm{jam}$, arah keluar 855 emp/jam.

b. Gerbang II Beji, tingkat kedatangan kendaraan arah masuk sebesar 905 emp/jam, arah keluar 687 emp/jam.

c. Gerbang III Bojong, tingkat kedatangan kendaraan arah masuk sebesar 994 emp/jam, arah keluar 994 emp/jam.

d. Gerbang IV Tulis, tingkat kedatangan kendaraan arah masuk sebesar 728 emp/jam, arah keluar 727 emp/jam.

e. Gerbang V Batang, tingkat kedatangan kendaraan arah masuk sebesar 849 emp/jam, arah keluar 849 emp/jam.

Jumlah gardu tol pada gerbang tol Pemalang - Batang tahun 2019 sebagai berikut:

a. Gerbang I Pemalang arah masuk terdapat 1 gardu tol otomatis khusus, 2 gardu tol otomatis dan 1 gardu tol on board unit, untuk arah keluar terdapat 1 gardu tol otomatis khusus, 3 gardu tol otomatis dan 1 gardu tol on board unit.

b. Gerbang I Beji arah masuk terdapat 1 gardu tol otomatis khusus, 4 gardu tol otomatis dan 1 gardu tol on board unit, untuk arah keluar terdapat 1 gardu tol otomatis khusus, 4 gardu tol otomatis dan 1 gardu tol on board unit.

c. Gerbang I Bojong arah masuk terdapat 1 gardu tol otomatis khusus, 4 gardu tol otomatis dan 1 gardu tol on board unit, untuk arah keluar terdapat 1 gardu tol
Tabel 16. Analisis Antrian Gerbang Tol

\begin{tabular}{|c|c|c|c|c|c|c|}
\hline \multirow{2}{*}{ Gerbang tol } & \multirow{2}{*}{\multicolumn{2}{|c|}{ Gardu Tol }} & $n$ & q & d & $\mathrm{w}$ \\
\hline & & & kend & kend & dtk & $\mathrm{dtk}$ \\
\hline \multirow{6}{*}{ Pemalang } & \multirow{2}{*}{ GTO khusus } & Masuk & 1,07 & 0,56 & 16,59 & 8,59 \\
\hline & & Keluar & 0,56 & 0,56 & 16,59 & 8,59 \\
\hline & \multirow{2}{*}{ GTO } & Masuk & 3,53 & 2,75 & 64,16 & 49,99 \\
\hline & & Keluar & 1,55 & 0,95 & 33,31 & 20,29 \\
\hline & \multirow{2}{*}{ OBU } & Masuk & 0,19 & 0,03 & 5,96 & 0,97 \\
\hline & & Keluar & 0,19 & 0,03 & 5,97 & 0,97 \\
\hline \multirow{6}{*}{ Beji } & \multirow{2}{*}{ GTO khusus } & Masuk & 0,32 & 0,08 & 10,60 & 2,58 \\
\hline & & Keluar & 0,14 & 0,02 & 9,11 & 1,11 \\
\hline & \multirow{2}{*}{ GTO } & Masuk & 4,35 & 3,53 & 84,67 & 68,85 \\
\hline & & Keluar & 3,66 & 2,87 & 87,20 & 68,50 \\
\hline & \multirow{2}{*}{ OBU } & Masuk & 0,08 & 0,01 & 5,41 & 0,41 \\
\hline & & Keluar & 0,03 & 0,00 & 5,19 & 0,19 \\
\hline \multirow{6}{*}{ Bojong } & \multirow{2}{*}{ GTO khusus } & Masuk & 0,95 & 0,46 & 15,62 & 7,62 \\
\hline & & Keluar & 1,80 & 0,46 & $\begin{array}{l}15,62 \\
\end{array}$ & 7,64 \\
\hline & \multirow{2}{*}{ GTO } & Masuk & 1,80 & 1,16 & 39,17 & 25,22 \\
\hline & & Keluar & 1,80 & 1,16 & 39,18 & 25,22 \\
\hline & \multirow{2}{*}{ OBU } & Masuk & 0,17 & 0,02 & \begin{tabular}{l|l|}
5,89 \\
\end{tabular} & 0,89 \\
\hline & & Keluar & 0,17 & 0,02 & 5,89 & 0,89 \\
\hline \multirow{6}{*}{ Tulis } & \multirow{2}{*}{ GTO khusus } & Masuk & 0,95 & 0,46 & 15,62 & 7,62 \\
\hline & & Keluar & 0,95 & 0,46 & \begin{tabular}{l|}
15,62 \\
\end{tabular} & 7,62 \\
\hline & \multirow{2}{*}{ GTO } & Masuk & 1,31 & 0,74 & 35,72 & 20,30 \\
\hline & & Keluar & 1,30 & 0,73 & 35,48 & 20,09 \\
\hline & \multirow{2}{*}{ OBU } & Masuk & 0,17 & 0,02 & 5,89 & 0,89 \\
\hline & & Keluar & 0,17 & 0,02 & \begin{tabular}{|l|l}
5,89 \\
\end{tabular} & 0,89 \\
\hline \multirow{6}{*}{ Batang } & \multirow{2}{*}{ GTO khusus } & Masuk & 1,08 & 0,56 & 16,67 & 8,67 \\
\hline & & Keluar & 1,08 & 0,56 & 16,70 & 8,67 \\
\hline & \multirow{2}{*}{ GTO } & Masuk & 1,02 & 0,51 & 26,33 & 13,30 \\
\hline & & Keluar & 1,03 & 0,52 & 26,52 & 13,49 \\
\hline & \multirow{2}{*}{ OBU } & Masuk & 0,19 & 0,03 & 5,97 & 0,97 \\
\hline & & Keluar & 0,19 & 0,03 & 5,97 & 0,97 \\
\hline
\end{tabular}

otomatis khusus, 4 gardu tol otomatis dan 1 gardu tol on board unit.

d. Gerbang I Tulis arah masuk terdapat 1 gardu tol otomatis khusus, 3 gardu tol otomatis dan 1 gardu tol on board unit, untuk arah keluar terdapat 1 gardu tol otomatis khusus, 3 gardu tol otomatis dan 1 gardu tol on board unit.

e. Gerbang I Batang arah masuk terdapat 1 gardu tol otomatis khusus, 2 gardu tol otomatis dan 1 gardu tol on board unit, untuk arah keluar terdapat 1 gardu tol otomatis khusus, 2 gardu tol otomatis dan 1 gardu tol on board unit.

\section{B. Saran}

Berdasarkan hasil perencanaan, berikut saran yang dapat diberikan oleh penyusun kepada perencana gerbang tol, badan pengelola jalan tol, ataupun pemerintah:

1. Sosialisasi penggunaan e toll card pada setiap pengguna jalan tol.

2. Mempermudah pengisian e-toll card

3. Memberi pengarahan agar pengendara golongan II sampai golongan $\mathrm{V}$ mau menggunakan alat $\mathrm{On}$ Board Unit.

4. Menggunakan harga yang terjangkau untuk pembelian alat On Board Unit.

\section{DAFTAR PUSTAKA}

[1] A. May, Traffic Flow Fundamentals. New Jersey: PrenticeHall International Inc, 1990.

[2] A. Erlang, Sejarah Teory Antrian dalam modul manajemen operasional. Jakarta, 1913.

[3] T. Kakiay, Dasar Teori Antrian Untuk Kehidupan Nyata. Yogyakarta: Andi Offset, 2004. 